\title{
Perfil da força de trabalho do INCA
}

\author{
Virginia Maria Leite de Almeida', Alina Reis Alves Junqueira², Eliane dos Santos de Oliveira ${ }^{3}$
}

\section{Resumo}

A análise do Perfil da Força de Trabalho do Instituto Nacional de Câncer, uma iniciativa da Coordenação de Recursos Humanos do INCA, tem como objetivo conhecer as características, a composição e a distribuição dessa força de trabalho, com vistas ao desenvolvimento de políticas de recursos humanos. Para tanto, foi realizado, nos períodos de 27/09 a 27/10/2004 e, posteriormente, entre 22/02 e 15/03/2005, um recadastramento funcional obrigatório dos servidores do Ministério da Saúde e dos funcionários contratados pela Fundação Ary Frauzino, que desenvolvem suas atividades na Instituição. A análise leva em conta informações sobre identificação pessoal, histórico escolar, grau de conhecimento sobre idiomas, produção científica acadêmica e profissional mais significativa, além de dados funcionais como: jornada e turno de trabalho, vínculo com a instituição, tempo de experiência profissional e de contribuição previdenciária. Dentre as características identificadas, verifica-se que as mulheres são a maioria (62,3\%). Seguindo a atual tendência da área da saúde, os trabalhadores com vínculo público são mais idosos e a graduação concentra-se na área da saúde (72,7\%).

${ }^{1}$ Coordenadora de RH/INCA.

${ }^{2}$ Gerente da Divisão de Projetos Estratégicos CRH/INCA.

${ }^{3}$ Consultora. 


\section{INTRODUÇÃO}

A análise do Perfil da Força de Trabalho do Instituto Nacional de Câncer (INCA) é uma iniciativa da Coordenação de Recursos Humanos no sentido de conhecer a composição e a distribuição dessa força de trabalho na Instituição, com vistas ao desenvolvimento de políticas de recursos humanos.

A composição do quadro funcional do INCA foi constituída, ao longo dos anos, por profissionais de diversas origens. O desconhecimento das características dessa força de trabalho quanto à sua distribuição e qualificação, pela ausência da coleta e sistematização de informaçôes, apontou a necessidade de um estudo que traduzisse o perfil desses profissionais, de modo a contribuir para o conjunto da Instituição no estabelecimento de seus planos de ação.

Para tanto, foi realizado um cadastramento/ recadastramento funcional obrigatório de todos os trabalhadores que desenvolvem suas atividades na Instituição.

O levantamento e a análise realizados levaram em conta informaçōes sobre identificação pessoal, histórico escolar e qualificação acadêmica, grau de conhecimento sobre idiomas, produção científica acadêmica e profissional mais significativa, além de dados funcionais como: jornada e turno de trabalho; vínculo com a instituição; tempo de experiência profissional e de contribuição previdenciária.

Esse procedimento foi essencial para o conhecimento da composição da força de trabalho da Instituição e, atualmente, como instrumento permanente de atualização, é estratégico para o estabelecimento de planos de ação da área de recursos humanos.

Este estudo, que busca reunir e consolidar informações sobre o corpo profissional da Instituição, é parte do processo de reformulação do papel da área de recursos humanos na direção de uma efetiva gestão do trabalho no INCA.

\section{INSTITUTO NACIONAL DE CÂNCER - INCA}

O Instituto Nacional de Câncer é um órgão do Ministério da Saúde que tem como missão desenvolver açôes nacionais visando à prevenção e controle do câncer e, como complexo hospitalar situado no Rio de Janeiro, agente prestador de serviços oncológicos no âmbito do SUS. Como Centro de Alta Complexidade em Oncologia (CACON) de referência do Ministério de Saúde, sua atuação em âmbito nacional está centrada na promoção, prevenção, assistência, pesquisa, educação e informação na área oncológica.

A estrutura do INCA compreende seis Coordenações:

\section{- Coordenação de Assistência}

A área de assistência médico-hospitalar é constituída por quatro Hospitais de Câncer e pelo Centro de Transplante de Medula Óssea. O Hospital de Câncer I (HCI) é estruturado para atender a doentes com todos os tipos de câncer. O Hospital de Câncer II (HC II) é um centro de referência na área de ginecologia oncológica. O Hospital de Câncer III (HC III) atua na prevenção e no diagnóstico do câncer de mama. $\mathrm{O}$ Hospital de Câncer IV (HC IV) é responsável pelo atendimento aos pacientes que necessitam de cuidados paliativos e pelo programa de internação domiciliar. $\mathrm{O}$ Centro de Transplante de Medula Óssea é responsável pelo tratamento de doenças do sangue, como a anemia aplástica e as leucemias, além de realizar transplante de medula óssea.

\section{- Coordenação de Prevenção e Vigilância (CONPREV)}

As ações educativas na área de prevenção e vigilância do câncer, além da análise e produção de dados técnicos e científicos sobre o câncer, são desenvolvidas pela CONPREV.

\section{- Coordenação de Pesquisa (CPQ)}

Esta Coordenação tem como linhas de pesquisa a biologia celular, a farmacologia, a genética, a medicina experimental e o acompanhamento da pesquisa clínica. - Coordenação de Ensino e Divulgação Científica (CEDC)

Cabe a esta Unidade a coordenação dos programas de formação de recursos humanos na área de controle do câncer, tanto os cursos de nível técnico quanto os cursos de pós-graduação lato sensu para profissionais médicos de diferentes áreas de especialidade, enfermeiros, físicos, nutricionistas, farmacologistas, fisioterapeutas, assistentes sociais, odontólogos, psicólogos e engenheiros.

\section{- Coordenação de Administração (COAD)}

A Coordenação de Administração é responsável pela gestão do ambiente hospitalar, pela gestão orçamentária e financeira, suprimento de bens e serviços e pela manutenção da infra-estrutura. Os contratos de prestação de serviços e postos de trabalho terceirizados estão sob a gerência desta Coordenação.

\section{- Coordenação de Açôes Estratégicas (COAE)}

Esta área coordena o planejamento estratégico institucional e a área de Tecnologia da Informação.

. Coordenação de Recursos Humanos (CRH) 
A Coordenação de Recursos Humanos é responsável pelo gerenciamento e execução de programas e projetos nas áreas de Desenvolvimento de RH, Gestão do Trabalho e Saúde do Trabalhador.

As atividades de Comunicação Social e Assessoria Jurídica estão vinculadas ao Gabinete da Direção Geral.

Desde 2003, o INCA vem passando por um processo de implantação e consolidação de um modelo de gestão participativo e compartilhado, que integra um Conselho Deliberativo como instância máxima de deliberação, compreendendo cinco Câmaras Técnico-Políticas: Atenção Oncológica, Inovação Científica, Informação, Educação e Comunicação, Incorporação Tecnológica e Desenvolvimento Institucional; uma Direção Executiva, formada por um colegiado composto pelos Coordenadores das suas diversas áreas de atuação; um Conselho Consultivo, formado por representantes de entidades de âmbito nacional e de usuários do SUS; e um Conselho de Bioética - ConBio, com a atribuição de assessorar a Instituição quanto à ética constante da Política Nacional de Prevenção e Controle do Câncer.

\section{FUNDAÇ̃̃O ARY FRAUZINO PARA PESQUISA E CONTROLE DO CÂNCER (FAF)}

A Fundação Ary Frauzino para Pesquisa e Controle do Câncer (FAF) é uma entidade filantrópica de direito privado, criada em 1991, com o objetivo de apoiar o INCA em sua função de órgão normativo e executor da Política Nacional de Prevenção e Controle do Câncer.

A cooperação entre o INCA e a Fundação Ary Frauzino foi formalizada por meio de dois instrumentos, firmados com a interveniência do Ministério da Saúde: o primeiro, assinado em 19 de julho de 1992, denominado Termo de Ajuste 01/92 e o segundo, assinado em 02 de agosto de 1995, chamado Convênio de Cooperação Técnica e Científica no 001 / FAF, renovado em agosto de 2005, por mais três anos.

Um dos objetivos do acordo firmado é o aprimoramento e a expansão da capacidade operacional do INCA, de forma a viabilizar o alcance dos seus objetivos quanto à prevenção e controle do câncer.

Entre outras ações, a FAF efetua contratações de pessoal e contribui, de forma substancial, na formação de recursos humanos, no desenvolvimento e na manutenção de pesquisas, no apoio a campanhas nacionais na área de prevenção e vigilância do câncer e na atualização tecnológica dos processos de trabalho.

A FAF tem papel estratégico na manutenção e no desenvolvimento institucional e humano do INCA por meio não só da contratação de profissionais especializados, mas também no suporte às ações de valorização do trabalhador e aperfeiçoamento do sistema de gestão.

\section{A FORÇA DE TRABALHO}

A força de trabalho do Instituto Nacional de Câncer (INCA), desde a sua criação em 1937 até 1980, era composta unicamente por servidores do Ministério da Saúde. A partir de então, até 1988, o quadro foi acrescido por profissionais vinculados à Campanha Nacional de Combate ao Câncer (CNCC), também pertencentes à estrutura do Ministério da Saúde, mas com características diferenciadas de modalidade de contratação. A CNCC possuía quadro de pessoal e plano de carreira próprios, contratando seus funcionários pelo regime da Consolidação das Leis do Trabalho (CLT).

Em 1988, como qualquer outro órgão público, a CNCC ficou impossibilitada de realizar novas contrataçōes e seu quadro funcional passou a ser regido pelo RJU, instituído pela Lei 8.112/90.

Somente em 1991, com a extinção da Campanha pelo Decreto $n^{\circ} 109$, os funcionários a ela vinculados foram definitivamente absorvidos pelo Ministério da Saúde e enquadrados nos cargos do Plano de Classificação de Cargos e Salários - PCCS, Lei no $5.645 /$ 70 e lotados no INCA.

Dos 1.936 servidores integrantes da Campanha, 336 profissionais, por determinação do Ministério da Saúde, permaneceram com seus cargos nas unidades de origem, INAMPS e Secretarias de Saúde Estadual e Municipal, onde estavam em efetivo exercício. Esta situação se mantém até hoje, com 225 profissionais exercendo seus cargos fora do INCA, apesar de sua lotação formal ser na Instituição. Destes servidores, 165 estão lotados em Unidades próprias do Ministério da Saúde no Rio de Janeiro, a saber: Hospital de Servidores do Estado, Hospital Geral de Bonsucesso e Instituto Nacional de Cardiologia Laranjeiras.

Em 1992, foram incorporadas ao INCA duas Unidades assistenciais com diferentes culturas e diferentes planos de cargos e salários: o Centro de Ginecologia Luiza Gomes de Lemos, órgão da extinta Fundação das Pioneiras Sociais do Ministério da Saúde e o Hospital de Oncologia, do extinto Instituto Nacional de Assistência Médica e Previdência Social (INAMPS).

Neste mesmo ano é firmado o Termo de Cooperação entre o INCA e a Fundação Ary Frauzino que, com a impossibilidade de contratações pelo Serviço Público, permitiu ao longo do tempo a reposição gradativa das necessidades de profissionais para o INCA. Essas novas incorporaçōes foram feitas, não apenas para garantir a manutenção das atividades realizadas pelo INCA, mas, principalmente, para a consecução da Política Nacional 
de Controle do Câncer, proposta pelo Ministério da Saúde.

Em 29/07/93, através da Lei 8.691/93, o INCA passou a integrar o Plano de Carreiras para a área de Ciência e Tecnologia, alcançando todos os servidores que estavam lotados na Instituição em 31/03/93. Em decorrência dessa Lei, foi estabelecido pelo Decreto Lei $\mathrm{n}^{\circ} 1.085$, de 14 de março de 1994, um quadro de pessoal composto de 3.541 servidores para o Instituto.

Embora desenvolvendo atividades semelhantes, os servidores provenientes do antigo quadro do Ministério da Saúde, da CNCC, da Fundaçãoo das Pioneiras Sociais, do INAMPS e os celetistas da FAF não somente recebiam remunerações diferentes como estavam vinculados a Plano de Cargos e Salários distintos e submetidos a legislaçôes específicas.

Com o intuito de minimizar essas diferenças, foi desenvolvido um Plano de Classificação de Cargos (PCC) interno do INCA, que se iniciou com o levantamento das atividades exercidas por cada servidor ou funcionário, seguido da criação de um conjunto de cargos hierarquizados, necessários ao funcionamento da Instituição. Todos os servidores do INCA, independente do vínculo de origem, do cargo ou nível hierárquico ocupado, foram enquadrados de acordo com suas atividades no PCC interno.

No momento atual, o quadro funcional do INCA agrega servidores estatutários com vínculo no Ministério da Saúde e funcionários celetistas contratados pela Fundação Ary Frauzino.

A diversidade de origens do conjunto da força de trabalho da Instituição requereu a realização deste estudo, de modo a possibilitar o conhecimento da sua composição e características em relação à sua distribuição.

\section{METODOLOGIA}

O presente estudo teve como população-alvo os servidores com vínculo público, pertencentes ou não ao quadro efetivo do Ministério da Saúde, que estão desenvolvendo suas atividades no INCA, e os trabalhadores contratados pela FAF, desde que não estivessem preenchendo vagas de substituição por prazo temporário.

Os contratos de serviço e de postos de trabalho terceirizados de apoio operacional e administrativo não foram contemplados neste levantamento. Da mesma forma, não foram incluídas as contratações na modalidade de substituição de licenças médicas prolongadas, realizadas pela Fundação Ary Frauzino.
Foram consideradas as seguintes situações como vínculo público:

Servidores do quadro efetivo do Ministério da Saúde

- Cargo ocupado por servidor público do quadro funcional do INCA, enquadrado no Plano de Carreiras para a área de Ciência e Tecnologia (PCC\&T) ou na Carreira da Seguridade Social e do Trabalho (CSST) por ter sido redistribuído ou removido para o INCA após 31 de março de 1993.

O servidor com duas matrículas ou mais está referenciado no quadro de força de trabalho apenas em uma matrícula, sendo priorizada a matrícula do cargo no PCC\&T.

\section{Servidores cedidos para outros órgãos}

- Servidores públicos do quadro efetivo do INCA, liberados para o exercício de Cargo Comissionado ou por Convênio de Cooperação Técnica, para outro órgão público das esferas Federal, Municipal, Estadual e do Distrito Federal.

\section{Servidores lotados em Hospitais Federais}

- Servidores Públicos contratados pela extinta Campanha Nacional de Combate ao Câncer (CNCC), para atuarem nos programas do INAMPS que foram absorvidos no quadro efetivo do MS e lotados no INCA, mas que estão desenvolvendo suas atividades em unidades próprias (Hospital dos Servidores do Estado, Hospital Geral de Bonsucesso e Instituto Nacional de Cardiologia Laranjeiras).

\section{Cargo em Comissão}

- Cargo ocupado em nível de direção, coordenação, assessoria, chefia de Divisão e Serviço (DAS). O servidor do quadro funcional do INCA nomeado para cargo DAS está incluído no quadro em seu cargo de origem.

\section{Cargo de Nomeação}

- Profissional sem vínculo efetivo com o serviço público nomeado para ocupar cargo em comissão.

- Servidor público das esferas Federal, Estadual, Municipal e do Distrito Federal liberado por seus órgãos de origem, para exercício de cargo comissionado no INCA.

\section{Cooperação Técnica}

- Servidor público das esferas Federal, Estadual, Municipal e do Distrito Federal liberado por seu órgão de origem para trabalhar no INCA mediante convênio de cooperação técnica.

Foram considerados como vínculo com a Fundação Ary Frauzino (FAF) os cargos ocupados por funcionários contratados, em regime de Consolidação das Leis Trabalhistas (CLT), nas seguintes modalidades:

- Contrato por prazo indeterminado ou determinado;

- Contrato por prazo determinado, mediante bolsa; 
Para obtenção dos dados foi desenvolvido, em parceria com a Divisão de Informática da Coordenação de Ações Estratégicas, um Banco de Dados que agrega o conjunto das informaçóes coletadas relativas a pessoal.

O Banco, para os casos de recadastramento, foi criado a partir da base de dados já existente referente à folha de pagamento da FAF e ao cadastro do SIAPE, utilizando como referência o número de matrícula.

O Banco de Dados criado permite a emissão de relatórios referentes a cada um dos itens contemplados, o autopreenchimento e a atualização permanente das informações pelo próprio trabalhador.

Para coleta dos dados foi elaborado um formulário de cadastramento/recadastramento funcional obrigatório, constituído de três blocos. O primeiro sobre identificação pessoal: idade, sexo, registro no Conselho Regional da classe, CPF, identidade, plano de saúde e local de residência. O segundo bloco enfocou informaçôes relativas ao histórico escolar, grau de conhecimento sobre idiomas, produção científica acadêmica e profissional mais significativa e o último bloco contemplou dados funcionais, como: jornada e turno de trabalho, modalidade de vínculo com a instituição, tempo de experiência profissional e de contribuição previdenciária.

Este formulário foi disponibilizado pela rede interna da Instituição (intranet) em dois períodos: 27/09 a 27/ 10/2004 e posteriormente entre 22/02 e 15/03/2005, para os servidores do Ministério da Saúde e os funcionários da Fundação Ary Frauzino. As chefias foram orientadas a facilitarem o acesso dos trabalhadores à intranet, ao mesmo tempo em que a $\mathrm{CRH}$ recebia aqueles com dúvidas e dificuldades de preenchimento.

Foi necessário reabrir o sistema no início de 2005, uma vez que foram identificadas inconsistências em 25\% dos formulários preenchidos e era significativo o número de pendências.

Os servidores cedidos para outros órgãos e os lotados nos hospitais federais (HGB, HSE e HCL) receberam tratamento diferenciado. A CRH realizou uma reunião com os gestores dos recursos humanos dos hospitais citados para esclarecimentos sobre o objetivo do projeto e sensibilização para a importância da obtenção desses dados. Foi ainda enviada uma correspondência individualizada para cada um desses servidores, contendo uma senha de acesso para o cadastramento na internet no período de 22/02 a 15/03/2005.

Os servidores afastados do país ou do Rio de Janeiro para participarem de cursos de doutorado e mestrado também receberam o mesmo tratamento. Os servidores em licenças médicas prolongadas não responderam ao recadastramento no período convencional, somente fazendo-o quando de seu retorno ao trabalho.

Em razão da base de dados utilizada e da complexidade de vínculos existentes no INCA, o processo de depuração dessa base foi demorado e requereu um olhar cuidadoso. A utilização inicial do número de matrícula como identificador contribuiu para essa situação, já que possibilitava que o mesmo servidor/ funcionário constasse relacionado em mais de uma situação de vínculo.

Esses casos se referiam, em especial, aos médicos com mais de uma matrícula no INCA, àqueles com vinculação inicial na extinta $\mathrm{CNCC}$ cujos contratos eram para uma jornada de $40 \mathrm{~h}$ e que, a partir de sua absorção pelo Ministério da Saúde e de seu enquadramento no plano de cargos e salários da Lei 5.645/70, tiveram seus contratos desdobrados em dois de $20 \mathrm{~h}$ semanais. Esses profissionais tiveram, por ocasião do enquadramento no Plano de Carreiras para a área de Ciência e Tecnologia, que optar entre sua inclusão nesta carreira, que determina a jornada de trabalho em $40 \mathrm{~h}$ semanais, ou a manutenção da sua situação anterior.

Outra situação decorrente do indicador utilizado diz respeito ao duplo vínculo entre o Ministério da Saúde e a FAF. No processo de depuração dos dados, ficou definido como vínculo principal o vínculo público e considerada apenas uma única matrícula.

Após o período de preenchimento dos dados, foi feita uma análise de consistência, quando se verificou que um número significativo de profissionais não havia respondido ao item sobre escolaridade, o que foi motivado por dois fatores diferenciados. O primeiro, relacionado à incompatibilidade dos equipamentos com a linguagem informatizada adotada, e o segundo pela falta de familiaridade com o mecanismo de gravação das informaçōes. Somado ao exposto, o sistema permitia que o funcionário enviasse os dados sem ter completado todas as informaçōes. Para sanar esses problemas a CRH, em parceria com a Divisão de Informática e os Núcleos de Recursos Humanos das Unidades Hospitalares, fez um mutirão, in loco, nas diversas Coordenações/ Unidades, com o intuito de buscar as informaçōes que ainda faltavam e de propiciar uma nova oportunidade para aqueles que ainda não tinham se cadastrado/ recadastrado.

Ao final desse procedimento, o cadastramento/ recadastramento foi concluído com $98 \%$ de respostas.

Para efeito da análise do perfil da força de trabalho, e com vistas a facilitar o processo de planejamento de recursos 
humanos, as informações foram agrupadas pelas grandes áreas de atuação do INCA: Assistência, Ensino, Pesquisa, Prevenção e Gestão, Planejamento e Infra-estrutura.

Dessa forma, as áreas estão assim constituídas:

- Na área de Assistência foram identificados todos os profissionais que trabalham nas unidades hospitalares: HC I, HC II, HC III, HC IV e CEMO, independente da sua formação;

- A área de Ensino incorporou a Coordenação de Ensino (CEDC);

- A área de Pesquisa, a Coordenação de Pesquisa (CPQ);

- A área de Prevenção incluiu a Coordenação de

Prevenção e Vigilância (CONPREV);

- Na área de Gestão, Planejamento e Infra-estrutura foram considerados as Coordenações de Administração, de Recursos Humanos, de Ações Estratégicas e o Gabinete da Direção.

As planilhas apresentam informações relativas ao conjunto da força de trabalho da Instituição e, também, estão desmembradas por tipo de vínculo: Ministério da Saúde e Fundação Ary Frauzino.

\section{Perfil da Força de trabalHo}

A força de trabalho do INCA tem como característica a multiplicidade de situações diferenciadas dentro do mesmo vínculo. A sua complexidade extrapola os números e a análise a seguir apresentados.

O levantamento aponta para a seguinte distribuição da força de trabalho por área de atuação do INCA: $82,7 \%$ profissionais desenvolvem suas atividades na área de assistência, $1,3 \%$ no ensino; $2,4 \%$ na pesquisa; $2,8 \%$ na prevenção e $10,8 \%$ na gestão (Tabela 1 ).

De um quantitativo de 3.245 trabalhadores, 56,1\% é composto por servidores do quadro efetivo do Ministério da Saúde e 43,9\% contratados pela Fundação Ary Frauzino.

Da composição da força de trabalho das áreas de pesquisa e prevenção, aproxidamente, $65 \%$ possuem vínculo FAF. A gestão e a assistência também possuem um
Tabela 1. Total da força de trabalho - INCA - novembro/2004 a março/2005

\begin{tabular}{l|c|c}
\multicolumn{1}{c|}{ Áreas de atuação } & Total & $\%$ \\
\hline Assistência & 2682 & 82,7 \\
\hline Ensino & 43 & 1,3 \\
\hline Pesquisa & 77 & 2,4 \\
\hline Prevenção & 91 & 2,8 \\
\hline $\begin{array}{l}\text { Gestão, planejamento e } \\
\text { infra-estrutura }\end{array}$ & 352 & 10,8 \\
\hline Total & 3245 & 100 \\
\hline
\end{tabular}

Fonte: CRH/INCA

número significativo desses contratos, em média $43 \%$. Por outro lado, o ensino detém o maior percentual de servidores públicos $(72,1 \%)$, apesar de ser a menor unidade, contando com apenas 43 profissionais (Tabela 2).

As mulheres são a maioria entre os trabalhadores do INCA (62,3\%), obedecendo as mesmas características apresentadas entre os servidores da saúde na esfera federal, onde $58,6 \%$ são do sexo feminino e $41,4 \%$ do masculino, segundo o Boletim de Pessoal no 7 do Ministério do Planejamento, Orçamento e Gestão. Dentre o conjunto das áreas, somente na de gestão, o número de profissionais do sexo masculino é maior $(60,8 \%)$ do que os das mulheres. Por outro lado, na área de prevenção $(69,2 \%)$, assistência $(65,3 \%)$ e pesquisa $(63,6 \%)$ estão as maiores concentrações do sexo feminino (Tabela 3$)$.

Interessante notar que, seguindo o mesmo perfil observado entre os servidores federais da área de ciência e tecnologia cuja idade média é de 46 anos, a faixa etária média da força de trabalho do INCA é de menos de 50 anos $(68,3 \%)$, com um detalhamento nítido: entre os mais idosos, ou seja, acima de 60 anos, em torno de $85 \%$ são vinculados ao Ministério da Saúde, e os mais jovens, com até 29 anos $(89,4 \%)$, são contratados pela FAF, refletindo os critérios de ingresso, que atraem os egressos dos programas de residência e dos cursos de especialização oferecidos pelo INCA (Tabela 4).

Tabela 2. Força de trabalho por vínculo - INCA - novembro/2004 a março/2005

\begin{tabular}{l|c|c|c|c|c}
\multicolumn{1}{c|}{ Áreas de atuação } & Total & MS & $\%$ & FAF & $\%$ \\
\hline Assistência & 2682 & 1527 & 56,9 & 1155 & 43,1 \\
\hline Ensino & 43 & 31 & 72,1 & 12 & 27,9 \\
\hline Pesquisa & 77 & 27 & 35,1 & 50 & 64,9 \\
\hline Prevenção & 91 & 31 & 34,1 & 60 & 65,9 \\
\hline Gestão, planejamento e infra-estrutura & 352 & 203 & 57,7 & 149 & 42,3 \\
\hline Total & 3245 & 1819 & 56,1 & 1426 & 43,9 \\
\hline
\end{tabular}

Fonte: $\mathrm{CRH} / \mathrm{INCA}$ 
Tabela 3. Funcionários e servidores por gênero segundo áreas de atuação - INCA - novembro/2004 a março/2005

\begin{tabular}{l|c|c|c|c|c}
\hline \multicolumn{1}{c|}{ Áreas de atuação } & Total & Masculino & $\%$ & Feminino & $\%$ \\
\hline Assistência & 2682 & 931 & 34,7 & 1751 & 65,3 \\
\hline Ensino & 43 & 21 & 48,8 & 22 & 51,2 \\
\hline Pesquisa & 77 & 28 & 36,4 & 49 & 63,6 \\
\hline Prevenção & 91 & 28 & 30,8 & 63 & 69,2 \\
\hline (CRH, COAD, COAE, DG) & 352 & 214 & 60,8 & 138 & 39,2 \\
\hline Total & 3245 & 1222 & 37,7 & 2023 & 62,3 \\
\hline
\end{tabular}

Fonte: CRH/INCA

Tabela 4. Funcionários e servidores por grupos de idades - INCA - novembro/2004 a março/2005

\begin{tabular}{l|c|c|c|c|c}
\multicolumn{1}{c|}{ Grupos de idades (em anos) } & Total & MS & $\%$ & FAF & $\%$ \\
\hline Até 29 & 301 & 32 & 10,6 & 269 & 89,4 \\
\hline 30 a 39 & 705 & 111 & 15,7 & 594 & 84,3 \\
\hline 40 a 49 & 1211 & 794 & 65,6 & 417 & 34,4 \\
\hline 50 a 59 & 825 & 708 & 85,8 & 117 & 14,2 \\
\hline 61 e mais & 203 & 174 & 85,7 & 30 & 14,8 \\
\hline Total & 3245 & 1819 & 56,1 & 1426 & 43,9 \\
\hline
\end{tabular}

Fonte: CRH/INCA

$\mathrm{Na}$ área de pesquisa concentram-se os profissionais mais jovens, na qual $52 \%$ têm menos de 40 anos. No ensino, $58,1 \%$ dos trabalhadores estão na faixa etária situada entre 40 a 49 anos. As áreas de assistência e gestão possuem um quadro mais maduro, ou seja, $27 \%$ têm mais de 50 anos (Tabela 5).

Quase todos os trabalhadores são provenientes do Rio de Janeiro $(85,3 \%)$ e moram na capital.

A análise por áreas aponta que, em média, $23 \%$ dos profissionais que atuam em pesquisa e prevenção são oriundos de outros estados. A gestão e o ensino são as áreas que congregam mais trabalhadores do interior do estado, respectivamente, $27,9 \%$ e $24,4 \%$ (Tabela 6 ).
O Qualivida - plano de assistência médico-hospitalar oferecido pela política de benefícios do INCA - é o plano de saúde mais utilizado pelos trabalhadores, ao qual $62,1 \%$ aderiram (Tabela 7 ).

Dentre os 3.245 trabalhadores do INCA que responderam ao recadastramento, 1.596 (49,2\%) têm nível superior, 1.093 (33,7\%) têm nível médio ou técnico e $556(17,1 \%)$ completaram o ensino fundamental.

A comparação com o perfil dos servidores de ciência e tecnologia federais, no qual 48\% têm nível superior; $44,4 \%$ têm nível médio e/ou técnico e $0,6 \%$ tem o ensino fundamental, mostra um padrão diferenciado, particularmente na proporção de servidores com nível fundamental.

Tabela 5. Funcionários e servidores por grupos de idades segundo áreas de atuação - INCA - novembro/2004 a março/2005

\begin{tabular}{l|c|c|c|c|c|c|c|c|c|c|c|c|c}
\hline \multicolumn{1}{c|}{ Áreas de atuação } & Total & $\begin{array}{c}\text { Até } \\
29\end{array}$ & $\%$ & $\begin{array}{c}30- \\
39\end{array}$ & $\begin{array}{c}40- \\
49\end{array}$ & $\begin{array}{c}50- \\
59\end{array}$ & $\begin{array}{c}60- \\
69\end{array}$ & $\begin{array}{c}70 \mathrm{e} \\
\text { mais }\end{array}$ \\
\hline Assistência & 2682 & 236 & 8,8 & 585 & 21,8 & 984 & 36,7 & 698 & 26,0 & 170 & 6,3 & 9 & 0,3 \\
\hline Ensino & 43 & 1 & 2,3 & 9 & 20,9 & 25 & 58,1 & 7 & 16,3 & 1 & 2,3 & 0 & 0,0 \\
\hline Pesquisa & 77 & 20 & 26,0 & 20 & 26,0 & 22 & 28,6 & 11 & 14,3 & 3 & 3,9 & 1 & 1,3 \\
\hline Prevenção & 91 & 11 & 12,1 & 20 & 22,0 & 42 & 46,2 & 14 & 15,4 & 3 & 3,3 & 1 & 1,1 \\
\hline $\begin{array}{l}\text { Gestão, planejamento e } \\
\text { infra-estrutura }\end{array}$ & 352 & 33 & 9,4 & 71 & 20,2 & 138 & 39,2 & 95 & 27,0 & 13 & 3,7 & 2 & 0,6 \\
\hline Total & 3245 & 301 & 9,2 & 705 & 21,7 & 1211 & 37,3 & 825 & 25,4 & 190 & 5,9 & 13 & 0,4 \\
\hline
\end{tabular}

Fonte: CRH/INCA 
O perfil diferencia-se também daquele encontrado nos servidores da saúde do nível federal, cuja distribuição é $25,5 \%$ de nível superior; $64,8 \%$ de nível médio e/ou técnico e $1 \%$ com ensino fundamental.

No caso dos trabalhadores de nível superior, a composição por área é a seguinte: $81,3 \%$ atuam na prevenção; $63,6 \%$ na pesquisa; $55,8 \%$ no ensino; $52,3 \%$ na gestão e 47,2\% na assistência (Tabela 8 ).

Considerando apenas os trabalhadores que possuem nível superior, observa-se que a maioria é proveniente de instituiçôes privadas - 76,9\% - e têm mais de 15 anos de formados. No entanto, esta configuração muda completamente se analisada por vínculo. A FAF possui $47,9 \%$ com menos de 10 anos de formados, e que se justifica, em parte, pela numerosa mão-de-obra jovem que compóe seu quadro (Tabela 9).

A graduação dos profissionais do INCA é concentrada em cursos da área de saúde $(72,7 \%)$, coerente com o seu perfil assistencial, seguidos de 2,3\% em cursos da área social, 1,7\% na área de humanas e $17,5 \%$ em outras áreas não correlatas com a saúde (Tabela 10).

Tabela 6. Funcionários e servidores por naturalidade segundo áreas de atuação - INCA - novembro/2004 a março/2005

\begin{tabular}{l|c|c|c|c|c}
\multicolumn{1}{c|}{ Áreas de atuação } & Total & Rio de Janeiro & $\%$ & Outros estados & $\%$ \\
\hline Assistência & 2682 & 2296 & 85,6 & 386 & 14,4 \\
\hline Ensino & 43 & 42 & 97,7 & 1 & 2,3 \\
\hline Pesquisa & 77 & 59 & 76,6 & 18 & 23,4 \\
\hline Prevenção & 91 & 71 & 78,0 & 20 & 22,0 \\
\hline Gestão, planejamento e infra-estrutura & 352 & 299 & 84,9 & 53 & 15,1 \\
\hline Total & 3245 & 2767 & 85,3 & 478 & 14,7 \\
\hline
\end{tabular}

Fonte: CRH/INCA

Tabela 7. Funcionários e servidores por tipo de plano de saúde segundo áreas de atuação - INCA- novembro/2004 a março/2005

\begin{tabular}{l|c|c|c|c|c|c|c}
\hline \multirow{2}{*}{ Áreas de atuação } & \multicolumn{7}{c}{ Planos de saúde } \\
\cline { 2 - 10 } & Total & Estatais & $\%$ & Qualivida & $\%$ & Outros & $\%$ \\
\hline Assistência & 2682 & 352 & 13,1 & 1681 & 62,7 & 649 & 24,2 \\
\hline Ensino & 43 & 8 & 18,6 & 22 & 51,2 & 13 & 30,2 \\
\hline Pesquisa & 77 & 7 & 9,1 & 47 & 61,0 & 23 & 29,9 \\
\hline Prevenção & 91 & 6 & 6,6 & 52 & 57,1 & 33 & 36,3 \\
\hline Gestão, planejamento e infra-estrutura & 352 & 65 & 18,5 & 213 & 60,5 & 74 & 21,0 \\
\hline Total & 3245 & 438 & 13,5 & 2015 & 62,1 & 792 & 24,4 \\
\hline
\end{tabular}

Fonte: CRH/INCA

Tabela 8. Funcionários e servidores por escolaridade segundo áreas de atuação - INCA - novembro/2004 a março de 2005

\begin{tabular}{l|c|c|c|c|c|c|c}
\hline \multirow{2}{*}{ Áreas de atuação } & \multicolumn{7}{c}{ Nível de escolaridade } \\
\cline { 2 - 9 } & Total & Fundamental & $\%$ & Médio & $\%$ & Superior & $\%$ \\
\hline Assistência & 2682 & 481 & 17,9 & 936 & 34,9 & 1265 & 47,2 \\
\hline Ensino & 43 & 10 & 23,3 & 9 & 20,9 & 24 & 55,8 \\
\hline Pesquisa & 77 & 7 & 9,1 & 21 & 27,3 & 49 & 63,6 \\
\hline Prevenção & 91 & 5 & 5,5 & 12 & 13,2 & 74 & 81,3 \\
\hline Gestão, planejamento e infra-estrutura & 352 & 53 & 15,1 & 115 & 32,7 & 184 & 52,3 \\
\hline Total & 3245 & 556 & 17,1 & 1093 & 33,7 & 1596 & 49,2 \\
\hline
\end{tabular}

Fonte: CRH/INCA 
Tabela 9. Funcionários e servidores por tempo de formado segundo áreas de atuação - INCA - novembro/2004 a março/2005

\begin{tabular}{l|c|c|c|c|c|c|c|c|c|c|c}
\hline \multicolumn{1}{c|}{ Áreas de atuação } & Total & $<$ de 4 & $\%$ & $5-9$ & $\%$ & $10-15$ & $\%$ & $16-24$ & $\%$ & $>$ de 24 & $\%$ \\
\hline Assistência & 1198 & 123 & 10,3 & 211 & 17,6 & 231 & 19,3 & 357 & 29,8 & 276 & 23,0 \\
\hline Ensino & 26 & 6 & 23,1 & 4 & 15,4 & 3 & 11,5 & 5 & 21,7 & 8 & 30,8 \\
\hline Pesquisa & 41 & 10 & 24,4 & 11 & 26,8 & 10 & 24,4 & 5 & 20,5 & 5 & 12,2 \\
\hline Prevenção & 65 & 8 & 12,3 & 13 & 20,0 & 8 & 12,3 & 22 & 33,8 & 14 & 21,5 \\
\hline $\begin{array}{l}\text { Gestão, planejamento } \\
\text { e infra-estrutura }\end{array}$ & 184 & 45 & 24,5 & 25 & 13,6 & 28 & 15,2 & 59 & 32,1 & 27 & 14,7 \\
\hline Total & 1514 & 192 & 12,7 & 264 & 17,4 & 280 & 18,5 & 448 & 29,6 & 330 & 21,8 \\
\hline
\end{tabular}

Fonte: CRH/INCA

Nota: Considerando os trabalhadores que possuem graduação, verifica-se que 82 não responderam a este quesito: (33 do MS e 49 do FAF).

Tabela 10. Funcionários e servidores por curso de graduação - INCA - novembro/2004 a março/2005

\begin{tabular}{l|c|c|c|c|c|c}
\hline \multirow{2}{*}{ Cursos de graduação por grandes áreas } & \multicolumn{6}{|c}{ Vínculos } \\
\cline { 2 - 7 } & INCA & $\%$ & MS & $\%$ & FAF & $\%$ \\
\hline Saúde & 1667 & 72,7 & 864 & 73,2 & 803 & 72,2 \\
\hline Medicina & 474 & 20,7 & 269 & 22,8 & 205 & 18,4 \\
\hline Enfermagem & 353 & 15,4 & 158 & 13,4 & 195 & 17,5 \\
\hline Odontologia & 5 & 0,2 & 2 & 0,2 & 3 & 0,3 \\
\hline Biológicas & 119 & 5,2 & 64 & 5,4 & 55 & 4,9 \\
\hline Outros cursos de saúde & 91 & 4,0 & 55 & 4,7 & 36 & 3,2 \\
\hline Sociais & 53 & 2,3 & 31 & 2,6 & 22 & 2,0 \\
\hline Humanas & 37 & 1,6 & 18 & 1,5 & 19 & 1,7 \\
\hline Engenharias & 15 & 0,7 & 9 & 0,8 & 6 & 0,5 \\
\hline Outras áreas & 401 & 17,5 & 194 & 16,4 & 207 & 18,6 \\
\hline Total & 2292 & 100,0 & 1180 & 100,0 & 1112 & 100,0 \\
\hline
\end{tabular}

Fonte: CRH/INCA

Nota: Neste quesito admitiu-se mais de uma resposta.

Do total dos 3.245 trabalhadores, 36,1\% têm pósgraduação lato sensu e 7,9\% têm cursos stricto sensu. A área de prevenção segue como a mais qualificada, se comparada com as demais, com um elevado índice de formação nas duas modalidades de pós-graduação stricto sensu: mestrado e doutorado $(60,4 \%$ e $38,5 \%$, respectivamente), seguida de perto pela área de pesquisa que possui $39 \%$ de profissionais com cursos stricto sensu (Tabela 11).

Detalhando por modalidades, nos 36\% que têm pós-graduação lato sensu, verifica-se que há um elevado número de trabalhadores com especialização $(83,1 \%)$ e um quantitativo menor com residência $(16,9 \%)$ (Tabela 12).

Tabela 11. Funcionários e servidores por modalidades de cursos de pós-graduação - INCA - novembro/2004 a março/2005

\begin{tabular}{l|c|c|c|c|c}
\multicolumn{1}{c|}{ Áreas de atuação } & Total geral & Lato sensu & $\%$ & Stricto sensu & $\%$ \\
\hline Assistência & 2682 & 973 & 36,3 & 169 & 6,3 \\
\hline Ensino & 43 & 18 & 41,9 & 6 & 14,0 \\
\hline Pesquisa & 77 & 25 & 32,5 & 30 & 39,0 \\
\hline Prevenção & 91 & 55 & 60,4 & 35 & 38,5 \\
\hline Gestão, planejamento e infra -estrutura & 352 & 100 & 28,4 & 15 & 4,3 \\
\hline Total & 3245 & 1171 & 36,1 & 255 & 7,9 \\
\hline
\end{tabular}

Fonte: CRH/INCA 
Tabela 12. Funcionários e servidores por modalidades de cursos de pós-graduação segundo áreas de atuação - INCA - novembro/2004 a março/2005

\begin{tabular}{l|c|c|c|c|c}
\hline \multirow{2}{*}{ Áreas de atuação } & \multicolumn{5}{c}{ Lato sensu } \\
\cline { 2 - 7 } & Total & Residência & $\%$ & Especialização & $\%$ \\
\hline Assistência & 973 & 182 & 18,7 & 791 & 81,3 \\
\hline Ensino & 18 & 6 & 33,3 & 12 & 66,7 \\
\hline Pesquisa & 25 & 2 & 8,0 & 23 & 92,0 \\
\hline Prevenção & 55 & 8 & 14,5 & 47 & 85,5 \\
\hline Gestão, planejamento e infra-estrutura & 100 & 0 & 0,0 & 100 & 100,0 \\
\hline Total & 1171 & 198 & 16,9 & 973 & 83,1 \\
\hline
\end{tabular}

\begin{tabular}{l|c|c|c|c|c|c}
\hline \multirow{2}{*}{\multicolumn{1}{c|}{ Áreas de atuação }} & \multicolumn{5}{c}{ Stricto sensu } \\
\cline { 2 - 7 } & Total & Mestrado & $\%$ & Doutorado & $\%$ \\
\hline Assistência & 169 & 120 & 71,0 & 49 & 29,0 \\
\hline Ensino & 6 & 5 & 83,3 & 1 & 16,7 \\
\hline Pesquisa & 30 & 16 & 53,3 & 14 & 46,7 \\
\hline Prevenção & 35 & 27 & 77,1 & 8 & 22,9 \\
\hline Gestão, planejamento e infra-estrutura & 15 & 11 & 73,3 & 4 & 26,7 \\
\hline Total & 255 & 179 & 70,2 & 76 & 29,8 \\
\hline
\end{tabular}

Fonte: CRH/INCA

Os $7,9 \%$ de trabalhadores que possuem cursos de pós-graduação stricto sensu são, na sua maioria, mestres $(70,2 \%)$ e doutores $(29,8 \%)$ (Tabela 12$)$. Os profissionais que possuem doutorado estão distribuídos da seguinte forma dentro do INCA: na área assistencial 64,5\%, na de pesquisa $18,4 \%$ e na de prevenção $10,5 \%$.

Dentre os 148 profissionais que têm pós-graduação stricto sensu e são vinculados ao Ministério da Saúde, 61,5\% têm mestrado e 38,5\%, doutorado. Já dos 107 vinculados à $\mathrm{FAF}, 17,8 \%$ são doutores e $82,8 \%$ mestres (Tabela 13 e 14).
Estes dados mostram a excelência de formação da força de trabalho do INCA e ficam mais expressivos quando comparados com as estatísticas sobre escolaridade da população. Segundo dados divulgados pelo IBGE, em torno de $30 \%$ dos brasileiros têm menos de quatro anos de estudo e cerca de $11 \%$ possui mais de 12 anos de estudo (IBGE, PNAD, 2003).

A jornada mais praticada pelos trabalhadores do INCA é a modalidade diarista e o turno de trabalho, o diurno, com exceção da área da assistência que possui $40,2 \%$ de seu quadro em regime de plantão (Tabela 15).

Tabela 13. Servidores por modalidade de curso de pós-graduação - INCA - novembro/2004 a março/2005

\begin{tabular}{l|c|c|c|c|c}
\hline \multicolumn{5}{c}{ Áreas de atuação } & \multicolumn{5}{c}{ Sinistério da Saúde } \\
\cline { 2 - 7 } & Total & Mestrado & $\%$ & Doutorado & $\%$ \\
\hline Assistência (HCl, HCII, HCIII, HCIV) & 107 & 67 & 62,6 & 40 & 37,4 \\
\hline Ensino (CEDC) & 3 & 3 & 100,0 & 0 & 0,0 \\
\hline Pesquisa (CPQ) & 14 & 5 & 35,7 & 9 & 64,3 \\
\hline Prevenção (CONPREV) & 16 & 10 & 62,5 & 6 & 37,5 \\
\hline Gestão, planejamento e infra-estrutura & 8 & 6 & 75,0 & 2 & 25,0 \\
\hline Total & 148 & 91 & 61,5 & 57 & 38,5 \\
\hline
\end{tabular}

Fonte: CRH/INCA 
Tabela 14. Funcionários por modalidade de cursos de pós-graduação - INCA - novembro/2004 a março/2005

\begin{tabular}{l|c|c|c|c|c}
\hline \multicolumn{2}{c}{ Áreas de atuação } & \multicolumn{5}{c}{ Stricto sensu } \\
\cline { 2 - 7 } & Total & Mestrado & $\%$ & Doutorado & $\%$ \\
\hline Assistência (HCI, HCII, HCIII, HCIV) & 62 & 53 & 85,5 & 9 & 14,5 \\
\hline Ensino (CEDC) & 3 & 2 & 66,7 & 1 & 33,3 \\
\hline Pesquisa (CPQ) & 16 & 11 & 68,8 & 5 & 31,3 \\
\hline Prevenção (CONPREV) & 19 & 17 & 89,5 & 2 & 10,5 \\
\hline Gestão, planejamento e infra-estrutura & 7 & 5 & 71,4 & 2 & 28,6 \\
\hline Total & 107 & 88 & 82,2 & 19 & 17,8 \\
\hline
\end{tabular}

Fonte: CRH/INCA

Tabela 15. Funcionários e servidores por tipo de jornada segundo áreas de atuação - INCA - novembro/2004 a março/2005

\begin{tabular}{l|c|c|c|c|c|c}
\hline \multirow{2}{*}{\multicolumn{1}{c|}{ Áreas de atua ção }} & \multicolumn{5}{c}{ Tipo de jornada } \\
\cline { 2 - 7 } & Total & Diarista & $\%$ & Plantonista & $\%$ \\
\hline Assistência & 2682 & 1604 & 59,8 & 1078 & 40,2 \\
\hline Ensino & 43 & 43 & 100,0 & 0 & 0,0 \\
\hline Pesquisa & 77 & 73 & 94,8 & 4 & 5,2 \\
\hline Prevenção & 91 & 91 & 100,0 & 0 & 0,0 \\
\hline Gestão, planejamento e infra-estrutura & 352 & 352 & 100,0 & 0 & 0,0 \\
\hline Total & 3245 & 2163 & 66,7 & 1082 & 33,3 \\
\hline
\end{tabular}

Fonte: CRH/INCA

Além da expressiva qualidade do quadro técnico, um pouco mais da metade dos trabalhadores do INCA declararam que falam, lêem e escrevem bem os três idiomas clássicos mais comumente utilizados (inglês, francês e espanhol).

Há poucos trabalhadores cedidos para o INCA, em torno de $1,1 \%$. O maior índice é observado na área de prevenção, onde há seis servidores cedidos, o que representa $19,4 \%$ do quadro da área.

Menos de um quarto da força de trabalho tem outro vínculo além do INCA. Dentre os trabalhadores que o possuem, grande parte está vinculada à assistência $(29,1 \%)$ e à pesquisa $(11,7 \%)$, áreas que por excelência agregam categorias profissionais cuja legislação permite a acumulação de vínculos como, por exemplo, médicos, enfermeiros, odontólogos, entre outros.

Os dados sobre a força de trabalho do INCA permitem apontar para dois perfis bem distintos: um vinculado ao MS, que possui cerca de $80 \%$ de trabalhadores com mais de 16 anos de experiência no mercado de trabalho e contribuição social, e um outro vinculado à $\mathrm{FAF}$, mais jovem, que tem quase a metade dos trabalhadores com menos de dez anos no mercado e, conseqüentemente, de contribuição social.

Finalizando, a Tabela 16 apresenta resumidamente o perfil da força de trabalho do INCA.

\section{CONCLUSÕES}

Informações sobre dados pessoais, formação e relação com o trabalho obtidas através deste estudo permitiram o conhecimento do perfil da força de trabalho, que é um componente importante tanto para as decisões gerenciais da área de Recursos Humanos quanto para as diversas Coordenaçóes e Unidades da Instituição, ampliando as parcerias internas e dando mais transparência à gestão.

O grande desafio, a partir deste estudo, está relacionado à elaboração de programas que atendam às expectativas de desenvolvimento e valorização da força de trabalho, na perspectiva do melhor desempenho institucional. A recomposição e a capacitação das equipes, através do seu redimensionamento adequado, podem também ser alimentadas pelos resultados deste estudo.

Este trabalho só foi possível porque contou com a participação dos profissionais da Instituição, que atenderam ao chamado para o preenchimento dos dados do Sistema de Informaçôes Gerenciais de Recursos Humanos SIGRH/INCA, elaborado em parceria com a Divisão de Informática da Coordenação de Ações Estratégicas. 
Tabela 16. Resumo do perfil da força de trabalho - INCA - novembro/2004 a março/2005

\begin{tabular}{|c|c|c|}
\hline \multirow{2}{*}{ Descrição } & \multicolumn{2}{|c|}{ Vínculo } \\
\hline & MS (1819) & FAF (1426) \\
\hline Total de trabalhadores & 56,1 & 43,9 \\
\hline Assistência & 56,9 & 43,1 \\
\hline Ensino & 72,1 & 27,9 \\
\hline Pesquisa & 35,1 & 64,9 \\
\hline Prevenção & 34,1 & 65,9 \\
\hline Gestão & 57,7 & 42,3 \\
\hline \multicolumn{3}{|l|}{ Grupos de idades (em anos) } \\
\hline Até 39 & 26,3 & 73,7 \\
\hline 40 a 49 & 65,6 & 34,4 \\
\hline 50 a 59 & 85,8 & 14,2 \\
\hline 60 e mais & 85,7 & 14,3 \\
\hline \multicolumn{3}{|l|}{ Origem } \\
\hline Outros estados & 17,9 & 12,1 \\
\hline Interior & 17,7 & 22,9 \\
\hline \multicolumn{3}{|l|}{ Nível de escolaridade } \\
\hline Fundamental & 22,8 & 10,0 \\
\hline Médio/Técnico & 31,8 & 36,0 \\
\hline Superior & 45,4 & 54,0 \\
\hline Lato sensu & 32,4 & 40,4 \\
\hline Stricto sensu & 8,1 & 7,5 \\
\hline Outros vínculos & 14,9 & 37,7 \\
\hline Experiência profissional (mais de 15 anos) & 73,5 & 26,2 \\
\hline Contribuição social (mais de 15 anos) & 82,1 & 29,0 \\
\hline
\end{tabular}

Fonte: CRH/INCA

\section{BIBLIOGRAFIA CONSULTADA}

1. Ministério do Planejamento, Orçamento e Gestão. Boletim de Pessoal no 107 de março de 2005.

2. Instituto Brasileiro de Geografia e Estatística (IBGE). Pesquisa Nacional de Amostra por Domicílio. Rio de Janeiro: IBGE; 2003.

3. Machado MH. Os médicos no Brasil. um retrato da realidade. Rio de Janeiro: FIOCRUZ; 1997.
4. Machado MH. Profissóes de saúde: uma abordagem sociológica. Rio de Janeiro, FIOCRUZ, 1995.

5. Instituto Nacional de Câncer (INCA). Relatório de Atividades. Rio de Janeiro: INCA; 2003.

6. Instituto Nacional de Câncer (INCA). Relatório de Atividades. Rio de Janeiro: INCA; 2004.

7. Fundação Ary Frauzino e Ministério da Saúde. Termo de Ajuste 01/92. 